of the science of optics is very apt to jump on the mere optician. Some of these gentlemen will give you a learned disquisition on acquired myopia, oblivious of the hereditary nature of this affection. Physicians; surgeons, general paractitioners, and all kinds of specialists may occupy the same or different planes, but there is a ligher plane to which, as Emerson said, we are all invited to ascend. There are many specialities not overpaid, and some well paid, and as a rule the least scientific are finaucially the strongest. The intellectuels should occupy the highest plane, if not in this world, then perhaps in the next.

You cannot raise physicians' fees by lowering those of the surgeons. There is no law in this country, except the inexorable la iv of supply and demand, to prevent any physician, if he so desire, from tixing his fee for his advice in his own consulting room at one hundred guiness, al ways provided that he is not on the panel, but $I$ am afraid that his sanity might be called in question,' and he might be relegated to the care of Dr. Mercier.

I am couvinced that many pliysicians, without making themselves ridiculous, could easily double their fees, especially those who are physicians to thr King or even to dukes and other notabilities. They could treat the notabilitics for the advertisement. A man like Dr. Mereier who holds a pre-eminent position in the mental worldI shall not say a world of lunacy for fear of being misunderstood-has no justification for charging a miserable fee He shonld demand such a fee as would mark the value of his advice.

Why should physicians trouble about their fees? According to the Rnyal College of Physicians, a fee is a mere houorarium, and no recompense for the superlative value of the advice tendered but not always swallowed. Why should this mere honorarium be fixed at one to three guineas for a consultation in the physician's house, with an addition of $14 \mathrm{~s}$. a mile for distance? Distance lends enchantment to the riew, and enormously enhances the value of the consultation-to the physician. I suppose if a patient offered an honorarium, consisting of a few of the snallest coins of the realm neatly folded up and enclosed in an envolope, to the President or C-nsor's of the College, it would be considered beneath their dignity to examine the contents of the envelope, at least not till the patient had departed-not from this life, but from the physician's sonsulting looms.

It is about time that physicians stopped this absurd twaddle about honorariums, and, like the surgeons and some specialists, put their fees on a somerwht more sensible footing. The cynic :might say, if the advice of both physicians and surgeons were alriays paid for on its intrinsic merits, it might be often recompensed by a very small coin. It is up to physicians and surgeons - to put a market value on their work, and the public can take it or leavo it as they think fit.

If 'the physicians' fees are too low, what about the unfortunate panel practitioner, who contracts to attend insured persons by the thousand for 365 days at a rate per head ranging from $5 \mathrm{~s}$. $8 \frac{1}{2}$ d. to $7 \mathrm{~s}$, without the accrued interest for thie sums remaining unpaid for a year or two? Of course he has a chance of a " floating sixpence,"; but that has usually sunk to the bottom of the stock mixture before he can lay hold of it. $\mathrm{He}$ certainly ouly gets an honor rium, and, if he do honest work, he earns his bread by the sweat of his brow. He used to get a guinea when he met a consultant, but now the consultation aud also a report on the patient are going to be included in the $7 \mathrm{~s}$., according to an agreement arranged between the Insurance Commissioners and the Insurance Acts Committee of the Buitish Medical Association. The unfortunate dupe is told by the latter body to keep his mouth shut for fear his honorarium be reduced. A chiropodist wonld not contract to cut your toe-nails for less than two guineas a year, and if you happened to die at the end of the first wonth, he would want his two guineas, and not $31 / 365$ ths of his capitation fec.

If it be seriously intended to lessen the surgeon's income, the best way to do it is not to employ him, but the surgeon well knows that competition is not over-lseen, and in the present state of medical knowledge his handicraft is not in danger. A celebrated surgeon once said to me, "There is alvays room at the top.". The surgeon thoulishes on the failures of general piagtitioners, and to a less extent on those of plysicians. The followiwg diseases, out of which the surgeons reap a rich harvest, are to a large extent preventable: Post.nasal adenoids, gastric and duodenal ulcers, appendicitis, colitis, intestinal stasis; to a considerable extent malignant: disease of : the various flexures :of the colon due, as Mctclinilizoff pointed ont, to stagnation; biliary and renal calculi, mastitis and eularged prostate. These diseases are medical in their initial stages, and I coald give an equally. long list of proventable diseases which remain medical to the finish. Although the general practitioners and physicians are ignominiously paid, they should not grudge the surgeon a liberal honorarium for wiping out or burying their mistakes. The late King Edward said: "If preventable, why not prevented?" Ah! there is the rub, and a hard nut for the Health Insurance Commissioners to crack. The only funny thing about the National Health Insurance Act is its name, as it is more closely related to a London fog than to any question of health; the only redeeming feature in the whole Act is the research work, and thero is only. spent on this the miserable sum of some $£ 50,000$ out of 25 to 30 millions steriing.

The preservation of health does not seem to be a paying game. My friend Ronald Ross has done more than any other man for the health of the tropics, and I would candidly ask him, Has he found it pay? Would he not.have been financially better off trifling with the health of tho nation as a National Health Insurance Commissioner. He.has, however, -something better than money - the high moral satifaction of work well done; and he may be, lilie Butler, "When turned to dust, presented with a monumental bust." ". When will the Legislature rise to a seuse of its duty, scrap all this cheap physic, and devote some attention to questions of bealth ?-I am, etc.,

Liverpool, Nov. 30th.

JAMES BARR.

Sir,-If any practical issue is to result from the interest. ing discussion raised by the late Sir' Lauder Brunton's letter, published by Sir Konałd Ross, we must, I thin̈k, try and get a little more down to root principles. Should wo not first define the services for which physicians and surgeons receive remuneration, before we endeavour to decide whether the remumeration is adequate or propcrly proportioned?

The services rendered by a surgeon which are comparable with those rendered by a physician are the investigation of the patient's condition, and the giving of advice as to the treatment to be arlopted. There is no service rendered by a physician which is at all comparable with the porformance of a surgical operation.

This being so, it seems to me that the question which really wants consideration is whether the renuneration which the medical profession receives for its advisoiry services and for its operative services respectively is properly distributed. Just as in general practice medical men have allowed the public to regard their chief service as the giving of medicine or the writing of a prescription. so have surgeons allowed the performance of their operatious al together to overshadow their equally responsible service of accurate diagnosis and sound advice as to the course that should be adopted. When one contrasts the size of a first class surgeon's fees for the preliminary consultation and for the subsequent laparotomy one is almost renrinded of the notices one sees put up by adrertising dentists, "Advice gratis." A.properly remunerative fee for the surgeon's examination and advice, even when such advice consists in recommending the patient to seek the help of a physician, would undoubtedly increase public contidence in its value. Such a fee should tend to remove the view apparently held by some of your medical correspondents that the surgeon is the servant of the plrysician: It would inevitably lead to a correspondmg: increase in the fee of the physician for his examination and advice. It might, advantageously I think, lead to a reduction in the tees charged for some surgical operations.

But if an attempt is to be made by concerted action to provide proper remuneration for both surgeons and physicians for their services in investigativg difficult cases and advising theieon; somo steps mnst also be talien to standardize the work for: which these larger fees are to be charged. 'A the which is a reasonable' reward for the serious responsibility involved in the thorough examina. tron of a difficalte case num in the giving of a ieusoned juedgement thereon, ean hafilly" be "reginded as otherwise "thau 
excessive for the investigation of any trivial ailment that an anxious or wealthy patient may be disposed to submit to a consultant. The securing of proper remuneration of physicians or surgeons for their advice in complicated cases seems almost necessarily to entail their refusal to allow the public unrestricted access to their consulting rooms. It will be necessary for us to take a leaf out of the book of the lawyers' professional regulations, and require the public to approach specialists and consultants only through the general practitioner, just as they approach barristers through solicitors. With this restricsion it should be quite possible to arrange that fees should not only be sufficient to reward adequately physicians and surgeons for their advice, but also on the advice of the general practitioner to increase the fee above the average when the complexity of the case or the special reputation of the consultant made such in. crease reasonable. It would enable us to meet the difficulties which are daily growing in consequence of the multitude of specialisms in the profession, which are inevitable with the increase of knowledge. A step in professional organization of this cliaracter would be an appropriate plank in the programme of our after-war reconstruction of medicine.-I am, etc.

Liondon, N.W., Nov. 28th. Lauriston E. Shaw.

Srr,-The question of physicians' and surgeons' fees is part of the larger one of remuneration in general. It is difficult to dogmatize on what constitutes legitimate pecuniary reward for scrvice. Theoretically it ought, I suppose, to be proportionate to the labour and skill involved in the service; and such is to a large extent the case-the skilled artisan earns more than the unskilled labourer, the lawyer than the skilled artisan, tho thian barrister than the dull one, etc. Nevertheless, the money given for service by no means always represents its real as distinguished from its market valuo. It is estimated that Shakespearc received at the most $£ 12$ for writing play. Today the value of the mere paper on which one of them, say Hamlet, was written would be pricelegs, and its discovery would send a thrill throughout the civilized world. Rembrandt died in porerty, his very existence having been forgotten by his compatriots, and we are told by one of his relatives that a generation after his death a portrait by him could have bcen purchased for sixpence Herbert Spencer earned so little by his writings that, but for an admirer on the other side of the Atlantic, ho could not hare continued his work. Darwin, fortunately, had independent means, or he could not have carried on his great work uuhampered, so small was its market value. Had he fallen into poverty, Government would, perhaps, have granted him a small annuity. A Ronald Ross makes a great discovery, the real value of which simply cannot be estimated in terms of money, and has to be content with the consciousness of the fact.

It is clear, therefore, that there is often a wide disparity between the real and the market value of service. Instances of this disparity abound. Some callings are more lucrative than others involving at least an equal degree of skill and labour. The butcher earns more than the greeayrocer, the hosice than the hairdresser, the stock. broker than the soldicr, and (coming to our own profession) the surgenon more than the physician.

If we probe the matter further we meet with yet stranger disparities. Thus, while Charlie Chaplin is said to be earning npwards of $£ 100,000$ a year, a Smith's prizeman of my acquaintance is barely able to secure a thousandth part of this sum. It takes several years to learn to be a carpenter, and his normal wage is at the rate of about one shifling an hour, while a young woman, after a three months' course of massage, can command her five to ten shillings an hour. A peasant, working from sunrise to sunset in producing the one form of wealth we cannot do without, gets three shillings a day (if as much), while a man who is "something in the city" will make his hundreds over a single deal.

I leare others to explain these incongruities. The practical fact to be borne in mind is that every one secures-and rightly so-as much as he can for his work, and the surge in is no exception to the rule. He is ablo to command higher, ees than the physician. Nor has the latter any scrous ground for complaint. When the medical student decides to become a pluysician rather than a sirgeon he does so with the full lnowledge that it is a less lucrative branch of tho profession.-I am, etc., Iondon. W., Dec. 3ra.

HARRY CAMPBELL.

Sir,-The discussion on the relative fees paid to specialists is interesting, but there must be many general practitioners like myself-physicians, surgeons, accoucheurs, and anaesthetists complete-who are wondering where they come in. I syringe out ears and do radical mastoids; I remove nasal polypi, adenoids, and tonsils; I do refractions; I remove teeth, giving my own gas or ether; I attend all infectious diseases, and do tracheotomy when necessary - the last one with the mother the sole assistant holding the solitary and shaking candle. I am a public vaccinator and the parish doctor. Paracentesis thoracis and abdominis are amongst iny accomplishments. I operate on perforated gastric ulcers, appendices, and all abdominal emergencies. "A strangilated hernia; please bring everything," takes me ten miles out in the middle of the night to operate on the case in a feather bed with a lamp and two candles as illumination. A pancreatic cyst, a uterus full of fibroids wedged in the pelvis, twisted ovarians, and prostatectomy are among my successes. Every conceivable obstetric emergency comes our way; we give our own chloroform and perform Caesarean section when occasion requires it. And in my spare time I delve into the mysteries of incurable diseases.

Last, but not least, I haro 1,500 insured persons under my care, with the unnecessary waste of time their coughs and colds and certificates take from more serious work.

Only recentiy I spotted two cases of . typhoid, in one of which I took the Widal reaction in my surgery, and thus, I suppose, performed some considcrable public service, as no more cases have developed; one was a panel patient who, by the way, had not had her medical card signed, the other a parish patient; thus, for this pubiic service, for the taking of two Widals and for the two notifications, I receirc 2s., less $4 d$. for stamps.

I agree $I$ am an adjective fool to do it, and I will take good care my sons do not; but there are dozens like me.

But; to return to the 100 -guinea argument, what fees would the specialists ask for doing my job for a year?

I enclose my card, but as the almighty Ego is some. what pronounced throughout the letter, let me sign myself, yours, otc.

December 4 til.

A Panel Doctor.

\section{FROG.SKIN GRAFTING}

Sir,- With reference to Captain Kendall's article on frog-skin grafting, in your issue of November 11th, may I be allowed to mention that this procedure was, I believe, initiated by myself when serving in India in the year 1884 ? On the principle "fiat experimentum," my first patient was my own corpus vile. 'I had for a long time suffered from an intractable ulceration (tropical ulcer) of the dorsum of the foot which had resisted all forms of treatment, including change to England, and I was begin. ning to despair of crer obtaining a cure. One day the Ressalcar Major of my regiment (5th Bengal Cavalry) sug. gested quite solemniy that $I$ should try cutting a frog in half and applying it to tho ulcorated surface, as he had known marvellous cures of ulcer effected by that means. I decided to accept his suggestion in so far as it com. mended itself to my judgement, and procured a frog, or rather several frogs, which I kept for a week in a ghurr. of boric lotion, and then used as sources of the grafts for my foot. The surface of the ulcer was in a sufficiently healthy state for grafting, and, to make a long story short, it was only about four or fire weeks, so far as my memory serves, before the whole surface was covered with sound and supple skin. 'To-day, thirty-two years later, it is impossible, save by the closest scrutiny, to discover the new skin. There is not the faintest trace of pigmentation, no contraction of the cicatrix ; the skin is practically indis. tingurshable from the original skin, and has stood the stress of thirty-two years' active wear and tcar.

So far as I can recollect, a full description of the skin grafting technique followed by me was published in the Indian Medical Gazctte of the year 1885 or 1886 , when had used it in a very large number of cases without, so 